\title{
Mapeamento das águas subterrâneas do município de Boa Vista do Cadeado/RS.
}

Groundwater mapping of Boa Vista do Cadeado city / rs.

\author{
José Luiz Silvério da Silva'; Leandro Meirelles do Nascimento²; Carlos Alberto Löbler³. \\ ' Geólogo Dr. Professor do Departamento de Geociências/PPGEAMB/PPGEC/CT/CCNE - RS - Brasil \\ ${ }^{2}$ Engenheiro Civil e Mestre em Engenharia Civil e Ambiental - PPGEC/UFSM - RS - Brasil \\ ${ }^{3}$ Geógrafo, mestrando do Programa de Pós Graduação em Engenharia Ambiental - PPGEAMB/UFSM - RS - Brasil
}

\section{Resumo}

A poluição gerada pelas atividades antrópicas tem despertado a necessidade contínua de conhecer e avaliar as condições do meio ambiente em relação a possíveis fontes de contaminação, principalmente as prejudiciais aos recursos hídricos subterrâneos. Por meio deste estudo, referente ao Município de Boa Vista do Cadeado, no Estado do Rio Grande do Sul, situado na Mesorregião noroeste riograndense, inserido na Província Geomorfológica do Planalto Meridional Brasileiro, onde afloram derrames de rochas vulcânicas formadoras do Sistema Aquífero Serra Geral/SASG. Espacializaram-se mapas temáticos referentes aos dados hidrodinâmicos dos poços tubulares tais como: nível estático, vazão, superfície potenciométrica, capacidade específica e índices de vulnerabilidade natural do aquífero à contaminação. Utilizando-se o sistema GOD, simularam-se 12 captações por poços. Foram obtidas duas classes de vulnerabilidade natural, sendo $83,3 \%$ na classe insignificante e $16,7 \%$ na baixa. Conclui-se que a região apresenta-se pouco vulnerável à contaminação, possuindo uma proteção natural, devido às camadas de rochas vulcânicas basálticas, em aquífero confinado e com um nível médio da água, pouco profundo.

Palavras-chave: vulnerabilidade, sistema GOD, SASG.

\begin{abstract}
The pollution generated by human activities has aroused the continuing need to know and assess the conditions of the environment in relation to possible sources of contamination, especially harmful to groundwater resources. Through this study, in the municipality of Boa Vista do Cadeado, in the state of Rio Grande do Sul, located in northwestern region, inserted in the Paraná Basin of the Southern Geomorphological Brazilian Plateau where spills outcrop of volcanic rocks forming the Serra Geral Aquifer System/SGAS. Were spatialized thematic maps related to hydrodynamic data of wells like: water table, underground flow, potentiometric surface, specific capacity and the index of natural vulnerability of the aquifer to contamination. Using the GOD method, were simulated by abstraction 12 wells. Were obtained two classes of natural vulnerability, circa the $83.3 \%$ in negligible class and $16.7 \%$ in low class. It was concluded that the region presented low vulnerability to contamination having a natural protection related to volcanic basalt rock layers, in a confined aquifer and water table near the surface.
\end{abstract}

Keywords: vulnerability, GOD method, SGAS. 


\section{INTRODUÇÃO}

O ser humano está diante do período crucial em sua existência, a biosfera do planeta Terra sofre impactos ambientais em grande escala, esta situação tem se agravado bruscamente neste século devido à interferência humana sobre os demais ecossistemas, causando mudanças climáticas e ambientais cada vez mais desastrosas para todas as espécies que habitam o planeta.

Os recursos naturais da Terra são explorados de forma desordenada, não sustentável, causando gradativo esgotamento dos mesmos.

A água é o principal recurso natural para a manutenção da vida no planeta Terra, tornou-se um bem de uso imprescindível ao desenvolvimento do ser humano. Portanto, surge a necessidade de executar-se o monitoramento contínuo, para garantir proteção contra contaminações, tanto nos ambientes superficiais, quanto nos subterrâneos. Visando a proteção desses recursos naturais.

A água subterrânea é parte essencial do ciclo hidrológico devido seu longo tempo de residência, ubiquidade, pequena variabilidade, fluxo estável e propriedades químicas pouco variáveis. Desempenha papel fundamental nos processos geológicos e biológicos, encerrando em si importantes implicações ambientais, como manutenção dos ecossistemas aquáticos e de todos os organismos que dependem, ou se relacionam a eles (Custódio e Silva Junior, 2008).

Essa preocupação ambiental potencializa muitos estudos, em diversos setores das ciências, e possibilita o aperfeiçoamento de tecnologias para monitoramento e prevenção contra impactos provenientes das atividades humanas sobre o meio ambiente natural.

O suporte teórico e prático neste trabalho está referenciado à hidrogeologia, por ser a ciência que estuda a água subterrânea presente na natureza, buscando sua quantificação, armazenamento e movimentação nos vários compartimentos terrestres, além do conhecimento dos seus mecanismos e processos intervenientes.

Este trabalho está inserido na área da Engenharia de Recursos Hídricos e Saneamento Ambiental, seu propósito principal busca a preservação do manancial subterrâneo e proteção contra impactos antropogênicos. Selecionou-se município do Estado do Rio Grande do Sul pertencente a Bacia Hidrográfica do Rio Ijuí - U90, segundo classificação da Sema (2004) ( U, refere-se a Bacia do Rio Uruguai, importante curso de águas, no noroeste do Estado, no qual a bacia está inserida).

$\mathrm{O}$ estudo inicia-se devido à detecção de uma problemática social, inerente aos municípios em expansão, onde áreas rurais transformam-se em urbanas aceleradamente, transpassando a capacidade de zoneamento ideal para as mesmas. Tal zoneamento urbano ideal deve ser baseado em informações que garantam a devida locação e uso do solo de forma otimizada e ambientalmente correta, relacionando o empreendimento às condições naturais do meio físico a ser explorado, bem como, às suas potencialidades e vulnerabilidades. O estudo da vulnerabilidade de aquíferos está previsto no código ambiental do estado, decreto $\mathrm{n}^{\circ} 11.520 / 2000$, no seu artigo 134 .

O problema observado, no município de Boa Vista do Cadeado, está relacionado à falta de informação e conhecimento sobre a vulnerabilidade do aquífero. Há proximidade da área de cultivo de soja, e de suas potenciais fontes de poluição difusa (FOSTER et al., 2006), como uso de agrotóxicos, pesticidas e fertilizantes (NPK), próximos aos pontos de captação de água subterrânea utilizados como fonte principal de abastecimento da comunidade Cadeadense (Nascimento, 2013).

O Estado do Rio Grande do Sul encontrase totalmente inserido nas regiões hidrográficas do Atlântico Sul e Uruguai. Na região do Rio Uruguai, na porção noroeste do estado, as disponibilidades hídricas superficiais são maiores. No entanto, essa região é caracterizada por longos períodos de estiagem e uso intenso de água para irrigação, o que compromete os mananciais utilizados para abastecimento urbano de água. Nessa parte do estado, em que o uso da água subterrânea é significativo, existe a presença de dois aquíferos sobrepostos, de grandes potencialidades hídricas: o Sistema Aquífero Serra Geral (SASG) e o Sistema Aquífero Guarani (SAG - Zona Confinada), com profundidades variáveis em função da paleotopografia (MACHADO; FREITAS, 2005 e ANA: ATLAS BRASIL, 2010).

Machado (2005) realizou estudos hidrogeológicos em escala regional do SAG, tanto em sua Zona de Afloramentos (ZA) quanto na Zona de Confinamento (ZC) (OEA/PEA/2009) onde se insere a área em estudo.

O sistema Aquífero é um conjunto composto de aquíferos livres, permeáveis, que permitem extração da água subterrânea; e aquíferos confinados, onde não há permeabilidade e mobilização significativa. (CUSTÓDIO; SILVA JUNIOR, 2008)

No Sistema Aquífero Serra Geral (SASG), foram realizados estudos de vulnerabilidade natural e risco de contaminação, porém, o foco era a ocorrência de atividade de suinocultura na Região das Missões, no Estado do Rio Grande do Sul, 
mesma região onde está inserida a área de estudo (NANNI et al., 2005 e FREITAS et al., 2012). Um outro estudo foi realizado por Silvério da Silva et al. (2013) na região de Erexim no Estado do Rio Grande do Sul no SASG.

Salienta-se que, o uso de mananciais subterrâneos, em pequenos municípios do Rio Grande do Sul, é bem superior ao uso de mananciais superficiais: 286 municípios do estado (Cerca de $59 \%$ ) são abastecidos exclusivamente por águas subterrâneas, enquanto que, as águas de superfície são utilizadas para o abastecimento de 134 sedes urbanas (28\%). Os demais municípios (13\%) são abastecidos de forma mista (mananciais superficiais e subterrâneos) (ANA: ATLAS BRASIL, 2010). $\mathrm{Na}$ zona de afloramento do SAG destacam-se os municípios de Santana do Livramento, Cacequi, São Pedro do Sul e Mata os quais são abastecidos por este sistema.

O abastecimento humano no Município de Boa Vista do Cadeado, tanto na área urbana, quanto rural, é executado por captações de água subterrânea através de poços tubulares, que captam águas do SASG, em profundidades de ate 250 metros (conforme serão apresentados nesse artigo), e são distribuídos e administrados pela Prefeitura Municipal (NASCIMENTO 2013).

A falta de informações e conhecimento sobre as condições do aquífero no Município de Boa Vista do Cadeado não favorece o planejamento ambiental adequado à expansão da área urbana sobre a rural, bem como, o desenvolvimento de atividades econômicas que garantam integridade do manancial subterrâneo explorado para abastecimento.

Este trabalho teve como objetivo mapear a vulnerabilidade do aquífero à contaminação no Município de Boa Vista do Cadeado/RS, com o uso do sistema $G O D$. E, também, espacializar as informações hidrodinâmicas do aquífero, por meio de mapas temáticos.

Aplicações do Sistema GOD Foster et al. (2006) na avaliação da vulnerabilidade do aquífero à contaminação foram executadas em várias pesquisas do Laboratório de Hidrogeologia do Departamento de Geociências da Universidade Federal Santa Maria/ Labhidrogeo (htttp://www. ufsm.br/labhidrogeo).

Em rochas sedimentares arenosas formadoras de aquíferos porosos intergranulares, na zona de afloramentos (ZA), do Sistema Aquífero Guarani/ SAG destaca-se; Terra et al. (2013) no Município de Santiago; Ertel et al. (2012) no Município de Rosário do Sul; Marion et al. (2010); Kemerich et al. (2011); Silvério da Silva e Descovi Filho (2010) no Município de Santa Maria e ainda, Martinez e Silvério da Silva (2008) no Município de Santa Cruz do Sul.

Já em rochas vulcânicas, formando aquíferos cristalinos fissurais pertencentes ao Sistema Aquífero Serra Geral/SASG cita-se Riffel e Silvério da Silva (2011) aplicaram o Sistema GOD no Município de Santa Rosa e Silvério da Silva et al (2013) em Erexim, ambos no Estado do Rio Grande do Sul.

\section{METODOLOGIA}

\section{I Caracterização da área de estudo}

O município de Boa Vista do Cadeado localiza-se no noroeste do Estado do RS e está localizado nas coordenadas pelo sistema SAD69: $-28^{\circ} 36^{\prime} 25^{\prime \prime} \mathrm{S},-53^{\circ} 48^{\prime} 54^{\prime \prime} \mathrm{W}$ (Figura 01) (IBGE, 2011). A área territorial do município perfaz cerca de 701,111 km². Localiza-se na Mesorregião noroeste riograndense e insere-se na Microrregião de Ijuí. Conta com uma população 2.441 habitantes (IBGE, 2010), com uma densidade demográfica baixa, de cerca $3,48 \mathrm{hab} . / \mathrm{km}^{2}$, apresentando características predominantes de zona rural (NASCIMENTO, 2013).

A aquisição de dados dos 12 (doze) captações por poços tubulares localizados dentro do perímetro do município de Boa Vista do Cadeado/ RS, foi realizada através de pesquisa no sítio do CPRM-SIAGAS, de incursões "in loco" e dos registros da prefeitura municipal de Boa Vista do Cadeado.

As informações adquiridas servem de dados de entrada para o SIG (sistemas de Informações Geográficas), georreferenciando a área do município. Os dados georreferenciados são utilizados para a confecção de mapas temáticos com o software SURFER $8.0^{\circledR}$, o qual utiliza a interpolação matemática, a fim de se obter resultados espacialmente analisados para posterior discussão (LANDIM et al. 2002).

Após a coleta de coordenadas com auxílio do GPS (Global Position System), as informações geográficas foram transferidas para o SIG ArcGIS, a fim de delimitar-se, e georreferenciar a área de estudo, para espacialização dos dados e execução da classificação temática.

A escolha do sistema $G O D$, ao invés de sistemas como DRASTIC (ALLER et al. 1987), vem da proposta de mapear áreas utilizando dados sem complexidade de aquisição, que possam ser coletados e correlacionados de forma simples, sem necessidade de muitos refinamentos hidrodinâmi- 


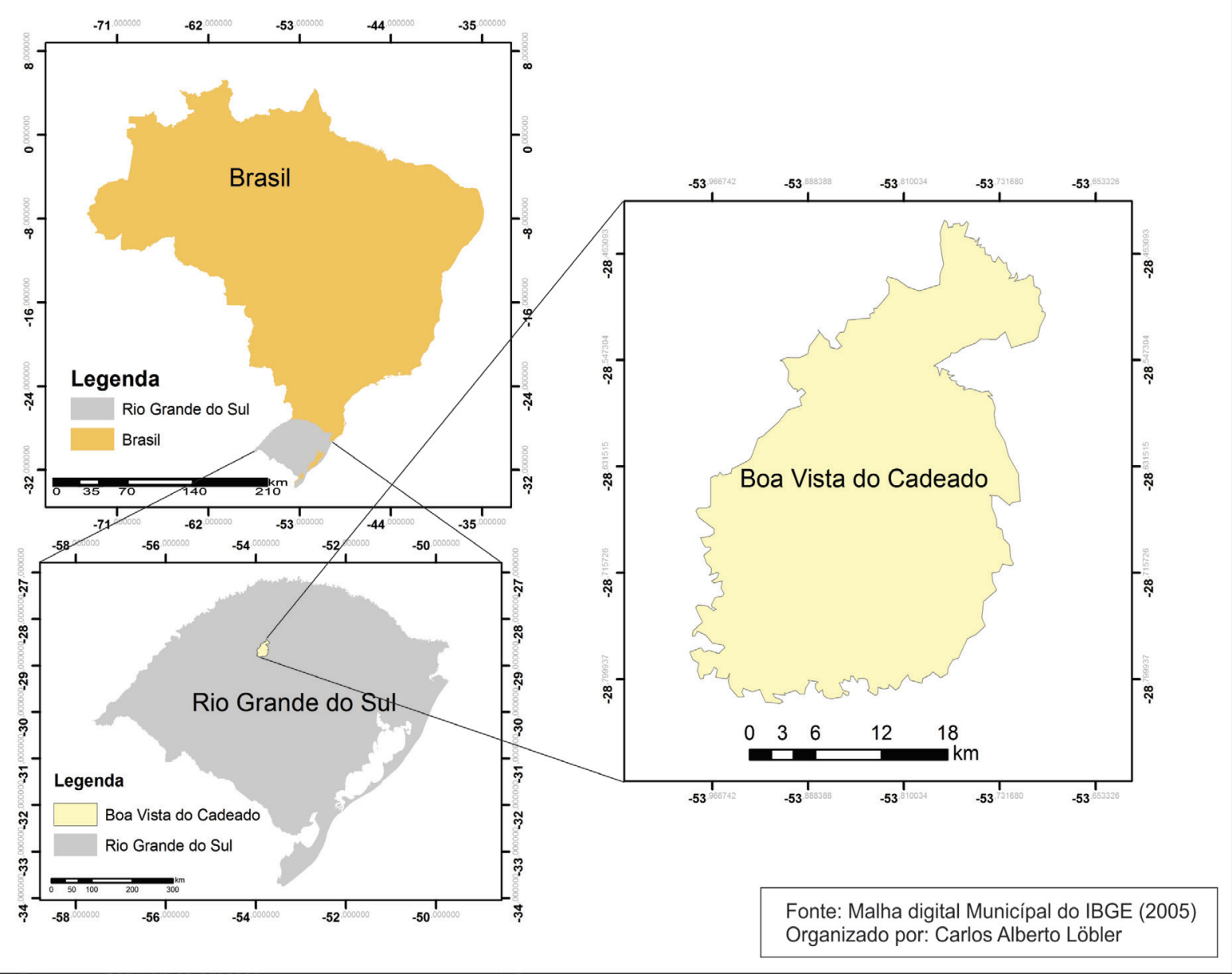

Figura 01- Localização do Município de Boa Vista do Cadeado/RS.

cos como por exemplo na aquisição do parâmetro $\mathrm{C}$ do DRASTIC. Esse refere-se a condutividade hidráulica que necessita de teste de bombeamento (rebaixamento x Tempo) de 24 horas de duração, e subsídios computacionais avançados, mas com representatividade de $100 \%$ do real e confiabilidade mínima de $99,95 \%$, para demonstração do cenário que está ocorrendo.

O sistema $G O D$ se torna uma ferramenta de tomada de decisões, pois aliado ao SIG, caracteriza claramente como é o comportamento da região estudada. Uma vez que foi desenvolvido para as condições brasileiras (FOSTER et al. 2006) onde existem normalmente poucas informações construtivas, hidrodinâmicas, hidrogeológicas das captações. Informa-se ainda que a grande maioria das captações não foram outorgadas pelo Departamento de Recursos Hídricos (DRH) e portanto não seguem o decreto estadual ${ }^{\circ}$ 42.047/2002 que exige além do teste de bombeamento de duração de 24 horas, análises físico-químicas completas da água subterrânea, a instalação do tubo lateral, hidrômetro e perímetro mínimo de proteção da captação com raio de $100 \mathrm{~m}$.

Para o cálculo do índice de vulnerabilidade natural do aquífero, segundo Foster; Hirata (2003), utilizando-se o sistema $G O D$, deve-se levar em consideração:

O Tipo de ocorrência da água subterrânea;

As características em termos litológicos (rochas penetradas na perfuração do poço) o grau de consolidação dos estratos acima da zona saturada;

A profundidade do nível freático ou teto do aquífero confinado.

Portanto fundamenta-se nas características intrínsecas ou naturais do meio penetrado, supondo-se que haja um derramamento ou carga contaminante na superfície do terreno.

Pelo sistema $G O D$, fundamentada em dados pré-existentes, atribuem-se valores a três tipos de parâmetros. Tais valores são multiplicados para se obter o índice de vulnerabilidade natural à contaminação (FOSTER et al. 2006). Ainda, segundo os autores, a partir dos mapas tematicos é realizada a análise da susceptibilidade à contaminação por 
poluentes, bem como, o possível trajeto subterrâneo dos mesmos ao atingirem o aquífero. Se existirem informações de carga contaminante elas complementam o sistema e enriquecer as análises em estudo.

O cálculo do índice de vulnerabilidade pelo sistema $G O D$, primeiramente necessita coletar-se informações, transformá-las em dados de entrada para a espacialização dos mesmos em SIG. Adotase como Datum horizontal SAD69 (South América Datum) e o Datum vertical o Porto de Imbituba/ SC para as avaliações dos fluxos subterrâneos. Na avaliação da superfície potenciométrica se estima a relação entre a "boca" do poço e o nível da água e com isso infere-se a direção de fluxo subterrâneo (HEATH, 1982/1983)

\section{DISCUSSÃO DOS RESULTADOS}

A aplicação do software ArcGIS 10 possibilitou a obtenção da área total do município e da malha urbana.Várias temáticas foram abordadas, sendo todas relacionadas as informações hidrogeológicas da área de estudo. Assim, puderam-se transformar as informações específicas em dados reais, de entrada, para o sistema GOD, no software SURFER. As principais informações que serviram de base para a geração de dados de saída, para conclusão de cada tema estudado, estão apresentados no quadro 01.

Deve-se observar que o terreno apresenta variabilidade na sua topografia, onde estão instaladas as perfurações por poços, variando entre um máximo de $420 \mathrm{~m}$ e um mínimo de $286 \mathrm{~m}$, ocupando assim diferentes derrames de rochas vulcânicas (quadro 01).

Nota-se no quadro 02 que a classe de vulnerabilidade predominante foi a insignificante, com cerca de $83,3 \%$ das captações inseridas, e apenas $16,7 \%$ das captações na classe baixa. Estes resultados indicam que a proteção natural oferecida pelos derrames de rochas vulcânicas, basaltos do SASG, podem ser considerados efetivos. Sendo que os aquíferos confinados dificultam a infiltração de água de precipitação pluviométrica e ou contaminantes gerados na superfície do terreno por atividades antrópicas distintas, como a contaminação difusa, no caso de predomínio das atividades agrícolas características da área estudada (FOSTER et al., 2006).

Quadro 01 - Características físicas e hidrodimâmicas dos doze poços tubulares cadastrados no Município de Boa Vista do Cadeado. (FOSTER et al., 2006 e NASCIMENTO, 2013)

\begin{tabular}{|c|c|c|c|c|c|c|c|c|c|c|c|}
\hline \multirow[b]{2}{*}{$\mathrm{n}$} & \multirow[b]{2}{*}{$\begin{array}{c}\text { Cota } \\
(\mathrm{m})\end{array}$} & \multicolumn{2}{|c|}{ Coordenadas (UTM) } & \multirow{2}{*}{$\begin{array}{l}\text { Prof. } \\
\text { Final } \\
\text { (m) }\end{array}$} & \multicolumn{2}{|c|}{ Níveis (m) } & \multirow{2}{*}{$\begin{array}{c}\text { Vazão } \\
\text { Estabilizada } \\
\left(\mathrm{m}^{3} / \mathrm{h}\right)\end{array}$} & \multirow{2}{*}{$\begin{array}{l}\text { Grau de } \\
\text { Conf. }\end{array}$} & \multirow{2}{*}{$\begin{array}{l}\text { Capacidade } \\
\text { Específica } \\
\mathbf{m}^{3} / \mathbf{h} / \mathbf{m}\end{array}$} & \multirow[b]{2}{*}{$\begin{array}{r}\text { Formação } \\
\text { geológica }\end{array}$} & \multirow[b]{2}{*}{ Localidade } \\
\hline & & $\mathbf{N} / \mathbf{S}$ & $\mathbf{E} / \mathbf{W}$ & & Estático & Dinâmico & & & & & \\
\hline 1 & 409 & 228608.08 & 6819541.69 & 101 & 38 & 44 & 7,5 & Confinado & 1,25 & Serra Geral & $\begin{array}{c}\text { Capela } \\
\text { Santana }\end{array}$ \\
\hline 2 & 365 & 212787.35 & 6813673.79 & 160 & 45 & 105,5 & 1,06 & Confinado & 0,017 & Serra Geral & $\begin{array}{c}\text { Bojo- Distrito } \\
\text { Cadeado }\end{array}$ \\
\hline 3 & 372 & 228060.09 & 6840769.38 & 90 & 36,61 & 46,5 & 10 & Confinado & 1,011 & Serra Geral & Faxinal \\
\hline 4 & 370 & 234246.67 & 6845359.84 & 248 & 61 & 65,82 & 13,2 & Confinado & 2,738 & Serra Geral & Faxinal II \\
\hline 5 & 385 & 226045.98 & 6823853.74 & 88 & 26,4 & 31,8 & 16,5 & Confinado & 3,055 & Serra Geral & $\begin{array}{l}\text { Alto Grande- } \\
\text { Capela }\end{array}$ \\
\hline 6 & 358 & 218704.22 & 6814194.56 & 75 & 12,7 & 19,85 & 9 & Confinado & 1,258 & Serra Geral & $\begin{array}{c}\text { Carlos Gama- } \\
\text { Ponte } \\
\text { Queimada }\end{array}$ \\
\hline 7 & 420 & 224181.44 & 6843140.58 & 72 & 38 & 44 & 8 & Confinado & 1,333 & SASG/SAG & $\begin{array}{l}\text { Rincão do } \\
\text { Tigre }\end{array}$ \\
\hline 8 & 375 & 225304.90 & 6834804.97 & 108 & 36,84 & 80,08 & 1,5 & Confinado & 0,034 & Serra Geral & $\begin{array}{c}\text { Pq. Rodeio- } \\
\text { Distr. Boa } \\
\text { Vista }\end{array}$ \\
\hline 9 & 286 & 221576.01 & 6837446.75 & 96 & 7,59 & 14,2 & 17,5 & Confinado & 2,647 & Serra Geral & Beira Rio \\
\hline 10 & 359 & 224542.07 & 6836595.63 & 82 & 13 & 30 & 10 & Confinado & 0,588 & Serra Geral & Beira Rio II \\
\hline 11 & 384 & 227118.22 & 6834015.52 & 49 & 36 & 36,48 & 13 & Confinado & 27,083 & Serra Geral & $\begin{array}{l}\text { Esquina } \\
\text { Quincas }\end{array}$ \\
\hline 12 & 357 & 219687.67 & 6836782.40 & 109 & 40 & 72 & 5 & Confinado & 0,156 & Serra Geral & Formigueiro \\
\hline
\end{tabular}


Quadro 02: Resultados obtidos da aplicação do sistema GOD aos doze poços tubulares cadastrados no Município de Boa Vista do Cadeado. (FOSTER et al., 2006 e NASCIMENTO, 2013)

\begin{tabular}{|c|c|c|c|c|c|c|}
\hline \multirow[b]{2}{*}{ Poço } & \multirow[b]{2}{*}{$\mathbf{G}$} & \multirow[b]{2}{*}{$\mathbf{O}$} & \multirow[b]{2}{*}{$\mathbf{D}$} & \multicolumn{2}{|c|}{ VULNERABILIDADE } & \multirow[b]{2}{*}{ LOCALIDADE } \\
\hline & & & & $\begin{array}{c}\text { Indice } \\
(\mathrm{G} \times \mathrm{O} \times \mathrm{D})\end{array}$ & Classe & \\
\hline 01 & 0,2 & 0,4 & 0,8 & 0,064 & Insignificante & Capela Santana \\
\hline 02 & 0,2 & 0,6 & 0,6 & 0,072 & Insignificante & Bojo, Distrito Cadeado \\
\hline 03 & 0,2 & 0,4 & 0,8 & 0,064 & Insignificante & Faxinal \\
\hline 04 & 0,2 & 0,8 & 0,9 & 0,144 & Baixa & Faxinal II \\
\hline 05 & 0,2 & 0,4 & 0,8 & 0,064 & Insignificante & Alto Grande-Capela \\
\hline 06 & 0,2 & 0,6 & 0,8 & 0,096 & Insignificante & Carlos Gama-Ponte Queimada \\
\hline $\mathbf{0 7}$ & 0,2 & 0,7 & 0,8 & 0,112 & Baixa & Rincão do Tigre \\
\hline 08 & 0,2 & 0,4 & 0,7 & 0,056 & Insignificante & Parque Rodeio-Distrito Boa Vista \\
\hline 09 & 0,2 & 0,4 & 0,8 & 0,064 & Insignificante & Beira Rio \\
\hline 10 & 0,2 & 0,4 & 0,8 & 0,064 & Insignificante & Beira Rio II \\
\hline 11 & 0,2 & 0,4 & 0,9 & 0,072 & Insignificante & Esquina Quincas \\
\hline 12 & 0,2 & 0,7 & 0,7 & 0,098 & Insignificante & Formigueiro \\
\hline
\end{tabular}

Quadro 03: Dados categorizados dos 12 poços tubulares cadastrados no Município de Boa Vista do Cadeado, para confecção dos mapas temáticos (cartogramas).

\begin{tabular}{|c|c|c|c|c|c|c|c|}
\hline \multirow{2}{*}{ Poço } & \multicolumn{2}{|c|}{ Coordenadas (UTM) } & \multirow{2}{*}{$\begin{array}{l}\text { Nível } \\
\text { Estático } \\
(\mathrm{m})\end{array}$} & \multirow{2}{*}{$\begin{array}{c}\text { Superfície } \\
\text { Potenciométrica } \\
(\mathrm{m})\end{array}$} & \multirow{2}{*}{$\begin{array}{l}\text { Vazão } \\
\left(\mathrm{m}^{3} / \mathrm{h}\right)\end{array}$} & \multirow{2}{*}{$\begin{array}{l}\text { Capacidade } \\
\text { Específica } \\
\left(\mathrm{m}^{3} / \mathrm{h} / \mathrm{m}\right)\end{array}$} & \multirow[b]{2}{*}{ Localidade } \\
\hline & $\mathrm{E}(\mathrm{m})$ & $\mathbf{N}(\mathrm{m})$ & & & & & \\
\hline 01 & 228608 & 6819541 & 38,00 & 371,00 & 7,50 & 1,250 & Capela Santana \\
\hline 02 & 212787 & 6813673 & 45,00 & 320,00 & 1,06 & 0,017 & $\begin{array}{c}\text { Bojo (Distrito } \\
\text { Cadeado) }\end{array}$ \\
\hline 03 & 228060 & 6840769 & 36,61 & 335,39 & 10,00 & 1,011 & Faxinal \\
\hline 04 & 234246 & 6845359 & 61,00 & 309,00 & 13,20 & 2,738 & Faxinal II \\
\hline 05 & 226045 & 6823853 & 26,40 & 358,60 & 16,50 & 3,055 & Alto Grande-Capela \\
\hline 06 & 218704 & 6814194 & 12,70 & 345,30 & 9,00 & 1,258 & $\begin{array}{c}\text { Carlos Gama-Ponte } \\
\text { Queimada }\end{array}$ \\
\hline 07 & 224181 & 6843140 & 38,00 & 300,00 & 8,00 & 1,333 & Rincão do Tigre \\
\hline 08 & 225304 & 6834804 & 36,84 & 338,16 & 1,50 & 0,034 & $\begin{array}{c}\text { Parque Rodeio-Distrito } \\
\text { Boa Vista }\end{array}$ \\
\hline 09 & 221576 & 6837446 & 7,59 & 278,41 & 17,50 & 2,647 & Beira Rio \\
\hline 10 & 224542 & 6836595 & 13,00 & 346,00 & 10,00 & 0,588 & Beira Rio II \\
\hline 11 & 227118 & 6834015 & 36,00 & 348,00 & 13,00 & 27,083 & Esquina Quincas \\
\hline 12 & 219687 & 6836782 & 40,00 & 317,00 & 5,00 & 0,156 & Formigueiro \\
\hline
\end{tabular}




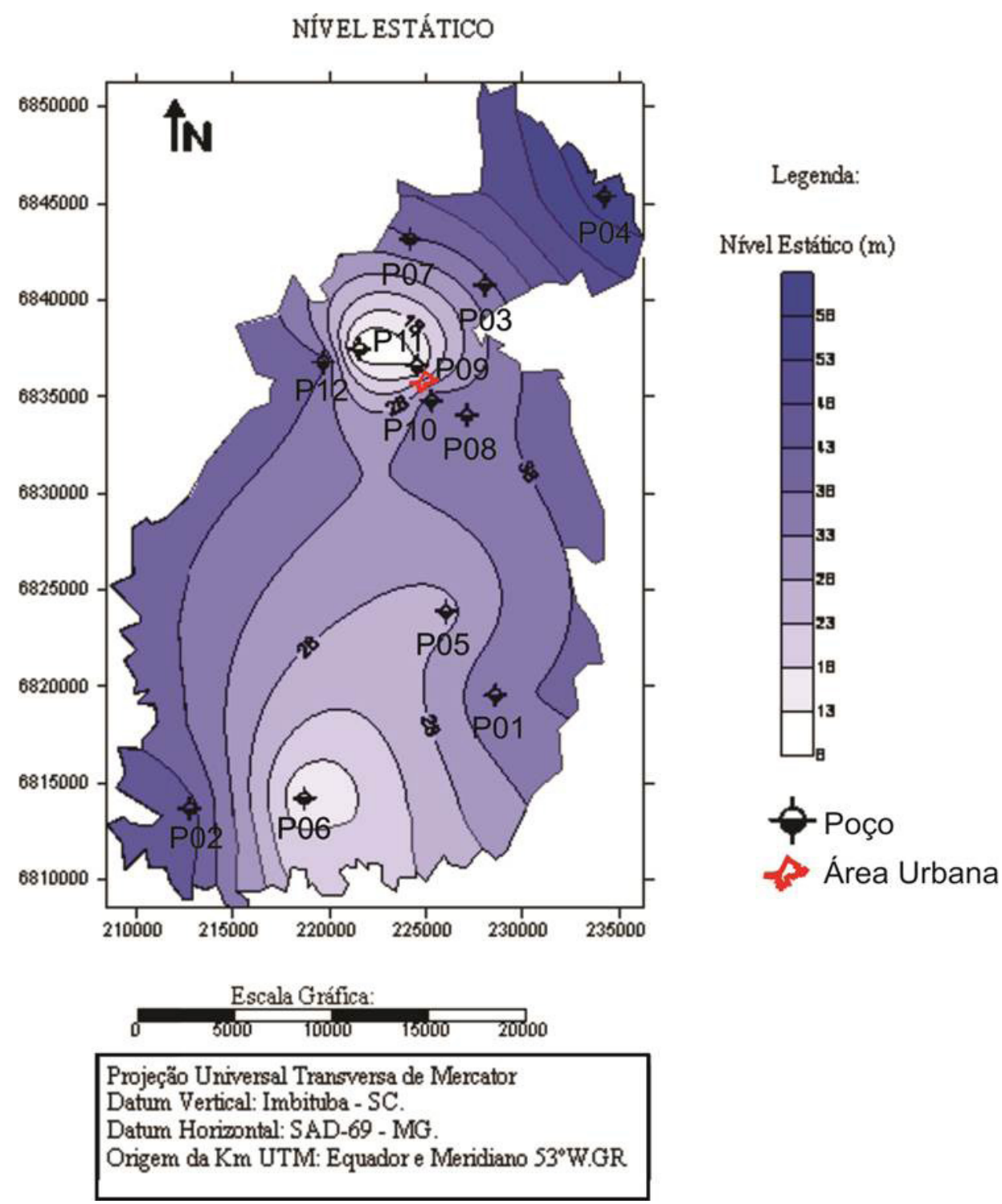

Figura 02 - Mapa referente ao Nível Estático dos poços tubulares mapeados no Município de Boa Vista do Cadeado/RS.

Notou-se que apenas o poço $\mathrm{n}^{\circ} 07$ na localidade de Rincão do Tigre penetra dois sistemas o SASG (basalto) e o SAG constituído por arenitos de interderrames. Esta captação foi cadastrada no SIAGAS/CPRM (2013) como poço 4300017259.

O quadro 03 apresenta os dados hidrodinâmicas de 12 poços tubulares usados na confecção dos cinco mapas temáticos (cartogramas), com uso do software SURFER $8.0^{\circledR}$, bem como, sua espacialização em SIG. Estes se referem ao Nível Estático, o qual dá uma ideia de sua profundidade, isto é a facilidade ou dificuldade de um contaminante atingir a água subterrânea. A Superfície Potenciométrica, que é indicativa da direção dos fluxos subterrâneos (HEATH, 1982 e 1983). O de vazão, que indica as áreas com maior produção de águas subterrâneas, juntamente com o de capacidade específica, que indica os locais de melhor recuperação do sistema aquífero em termos de bombeamento para usos multiplos. Finalmente, o de vulnerabilidade, que espacializa as áreas mais susceptíveis à contaminação (desde que haja uma carga contaminante), podendo ser utilizado no planejamento do uso e ocupação dos solos na área urbana e rural do município.

Depois de elaboradas as planilhas no software Microsoft Excel, são transferidos os dados para o software SURFER $8.0^{\circledR}$, para elaboração dos mapas e para avaliação da vulnerabilidade natural. Os dados, gerados das coletas de informações do portal do CPRM-SIAGAS, dos registros da Prefeitura Municipal e das visitas de campo, foram espacializados e analisados por meio dos mapas apresentados nas Figuras 02, 03, 04, 05 e 06.

Por meio da avaliação realizada em relação as variações do nível estático no mapa (Figura 02), 


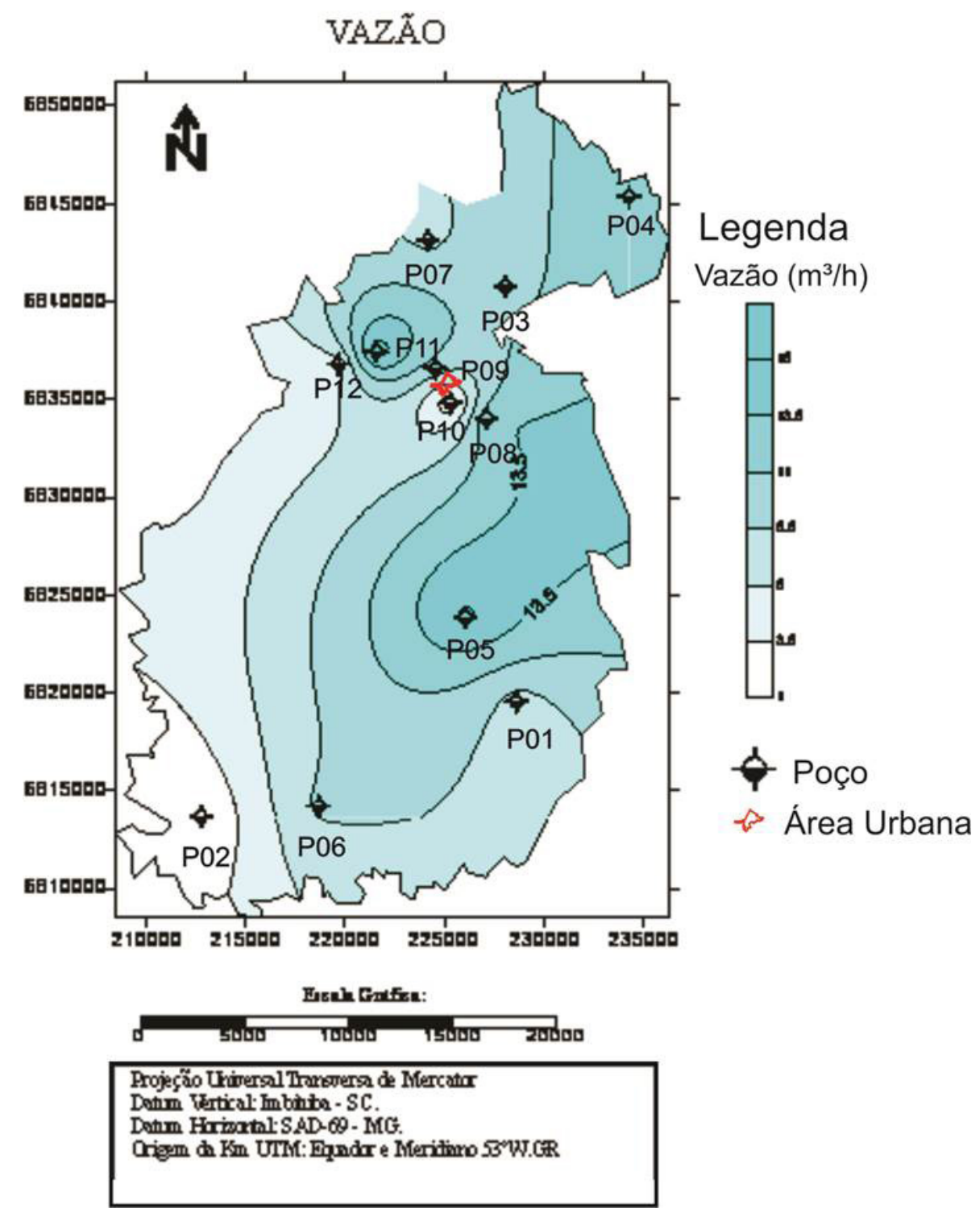

Figura 03 - Mapa da Vazão dos 12 poços tubulares mapeados no Município de Boa Vista do Cadeado/RS.

observa-se que os poços com maior coluna de água disponível localizam-se próximos à divisa com os demais municípios. Enquanto que os poços mais rasos, com menor coluna de água, estão no interior da área do município, portanto, deve-se dar atenção a esta condição no momento em que intensificarem-se as atividades produtivas na parte central do município, pois os poços mais rasos recebem alimentação freática em sua recarga, tornando-os mais suscetíveis a cargas de poluentes.

Referece em relação ao parâmetro ( $\mathrm{D}=$ Depth), as faixas de variação do nível da água (quadros 01 e 03) em classes nos 12 poços estudados são: estudada;

N.E. $<5 \mathrm{~m}$ ocorreram zero poços na área

N.E. (5- 20m) ocorreram três poços, representando $25,0 \%$ na área;
N.E. (20-50m) ocorreram oito poços, representando $66,7 \%$ na área. Portanto, a faixa de variação predoninante, o que irá influir grandemente nos resultados de ìndice de vulnerabilidade de classes (baixa e insignificante);

N.E. $(>50 \mathrm{~m})$ ocorreu em apenas um poço (P04), na localidade de Faxinal II.

A média dos níveis estáticos foi de $32,59 \mathrm{~m}$, os quais penetram vários tipos de meios geológicos, incluindo: solos argilosos, areia siltosa e arenitos porosos (como no poço (P07), na localidade de Rincão do Tigre). Todos são confinados por derrames de rochas vulcânicas maciças, como no poço (P07), o que determina uma boa proteção natural do manancial subterrâneo em relação à contaminação.

As figuras 02, 03, 04, 05, 06 apresentam diferentes mapas tematicas ou cartogramas para 

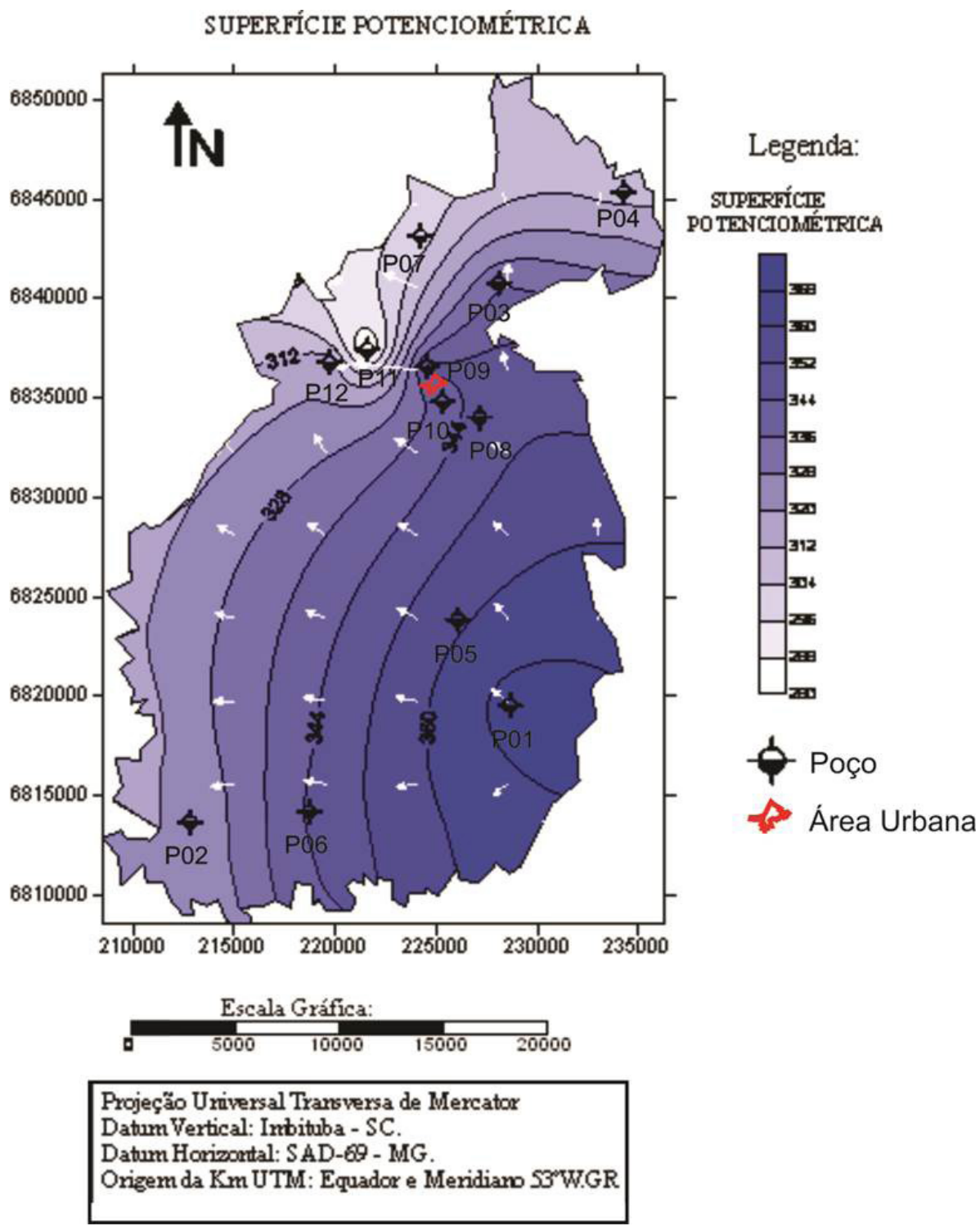

Figura 04 - Mapa da Superfície Potenciométrica dos 12 poços tubulares mapeados no Município de Boa Vista do Cadeado/RS.

cada parametro avaliado em doze captações.

Notou-se que ha uma ampla variabilidade no nivel da água nas distintas localidades, possivelmente associados a distintos derrames vulcanicos não continuos.

Avaliando-se as vazões após estabilização, apresentadas no mapa da figura 03 e no quadro 03 , observa-se que ela variou de $1,06 \mathrm{~m}^{3} / \mathrm{h}$, no poço (P02), na localidade de Bojo-Distrito de Boa Vista, localizado na porção extremo sudoeste do cartograma. Já a maior vazão, de $17,50 \mathrm{~m}^{3} / \mathrm{h}$, ocorreu no poço (P09), na localidade de Beira Rio, na porção central do cartograma. Também merece atenção à vazão elevada de $16,5 \mathrm{~m}^{3} / h$ no poço (P05), na localidade de Alto Grande-Capela, na porção central do cartograma.

Avaliando-se os valores da superfície potenciométrica (Figura 04), observa-se que a hidráulica minima encontrada foi de 278,41 m no poço (P09), na localidade de Beira Rio. Já o maior valor de carga ocorreu no poço (P01) $371,00 \mathrm{~m}$ na localidade de Capela Santana localizado no extremo sudeste do cartograma. Apresentando um desnível de $92,59 \mathrm{~m}$. Portanto inferiu-se um fluxo de direção sudeste para sudoeste/nordeste, ficando assim definida a direção do fluxo subterrâneo. Essa condição delimita onde um possível contaminante poderia migrar se atingisse o SASG e/ou o teto do aquífero confinado SAG. Observar a ocorrência de dois altos potenciométricos localizados no poço (P01 e P05) na de Capela Santana. Enquanto na porção norte da área avaliada formase uma Depressão Potenciométrica, onde as cargas hidráulicas subterrâneas são menores representadas pelos poços (P11) na localidade Beira Rio e (P10) Beira Rio II, indicando uma possível contribuição 


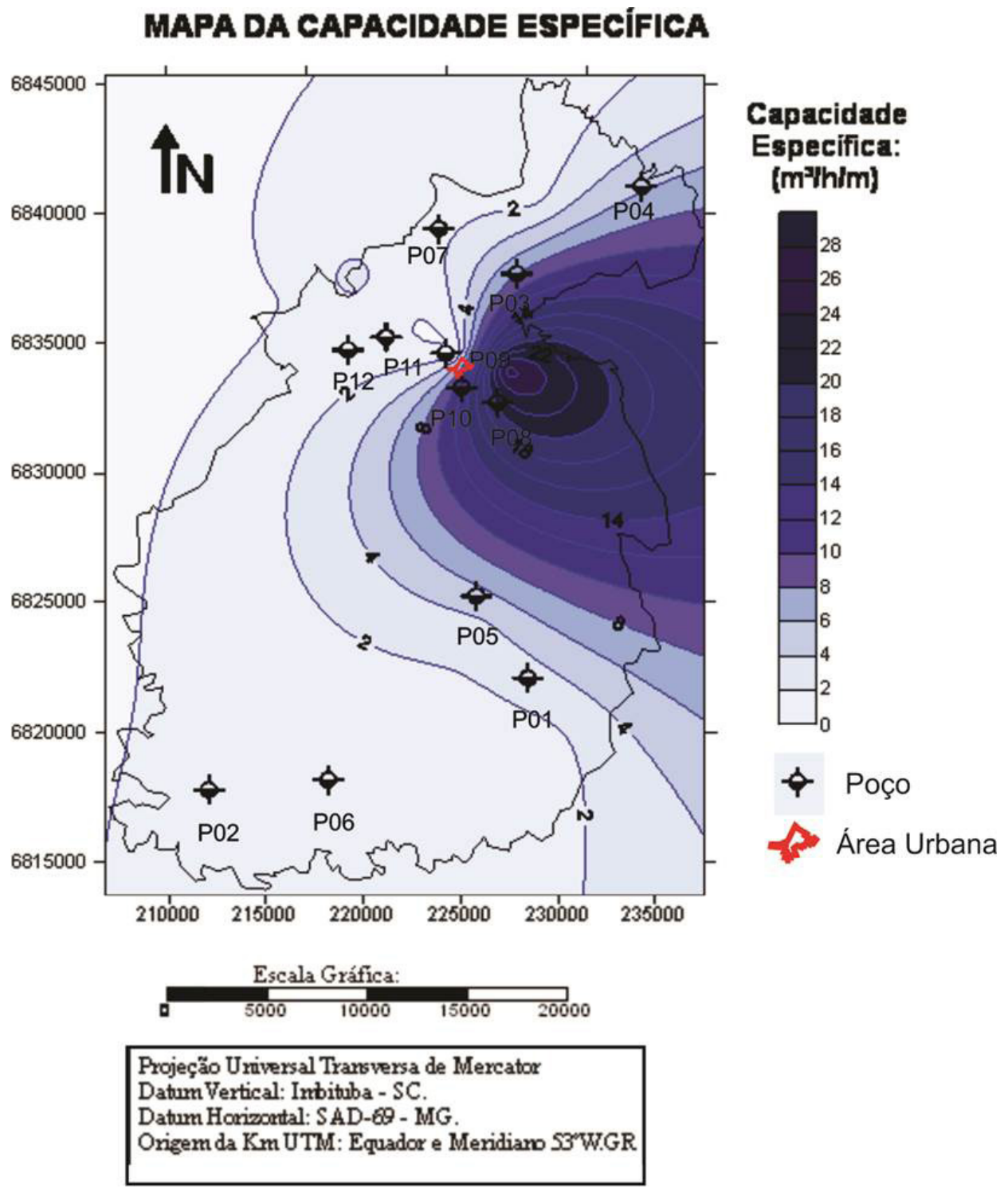

Figura 05 - Mapa da Capacidade específica dos 12 poços tubulares mapeados no Município de Boa Vista do Cadeado/RS.

subterrânea na perenização do Rio Conceição e ainda na manutenção do nível de base do Rio Ijuí, afluente do Rio Uruguai, Bacia Hidrográfica do Ijui- U-90 (SEMA, 2004).

A capacidade específica (HEATH, 1983), ou vazão específica (Figura 05), é um indicativo da capacidade real de explotação de água subterrânea. Encontrou-se cerca de $67 \%$ dos poços com capacidade específica até $2 \mathrm{~m}^{3} / \mathrm{h} / \mathrm{m}$, caracterizando a região em estudo como pertencente à de aquíferos de alta a média possibilidade para águas subterrâneas, em rochas com porosidade por fraturas, e do Sistema Aquífero Serra Geral I (MACHADO; FREITAS, 2005) apresentada no Mapa Hidrogeológico do Estado do Rio Grande do Sul.

Observou-se que o menor valor deste parâmetro ocorreu no poço (P02) e foi de $0,017 \mathrm{~m}^{3} / \mathrm{h} / \mathrm{m}$, quadro 03, na localidade Bojo (Distrito de Cadeado), situado na porção sudoeste da área estudada. Enquanto o maior valor $27,083 \mathrm{~m}^{3} / \mathrm{h} / \mathrm{m}$ ocorreu no poço (P11), na localidade de Esquina Quincas, situado na porção centro-norte da área do estudo. Esse valor de capacidade específica está muito acima daquele descrito por (MACHADO; FREITAS, 2005), no mapa hidrogeológico do Estado do Rio Grande do Sul para o Sistema Serra Geral I. Essa elevada produção pode ser resultado de fraturas abertas associadas aos Sistemas de Fraturas Terra de Arreia/Possadas (SFTAP) e ao Sistema de Falhas Jaguari/Mata (SFJM) (MACHADO, 2005), de direção NW, onde se encontra parcialmente encaixados o Rio Ijuí. Nesse poço pode haver formação de porosidade secundaria.

Estes sistemas de falhas se estendem desde o município de Cruz Alta, localidade de Boa Parada, 


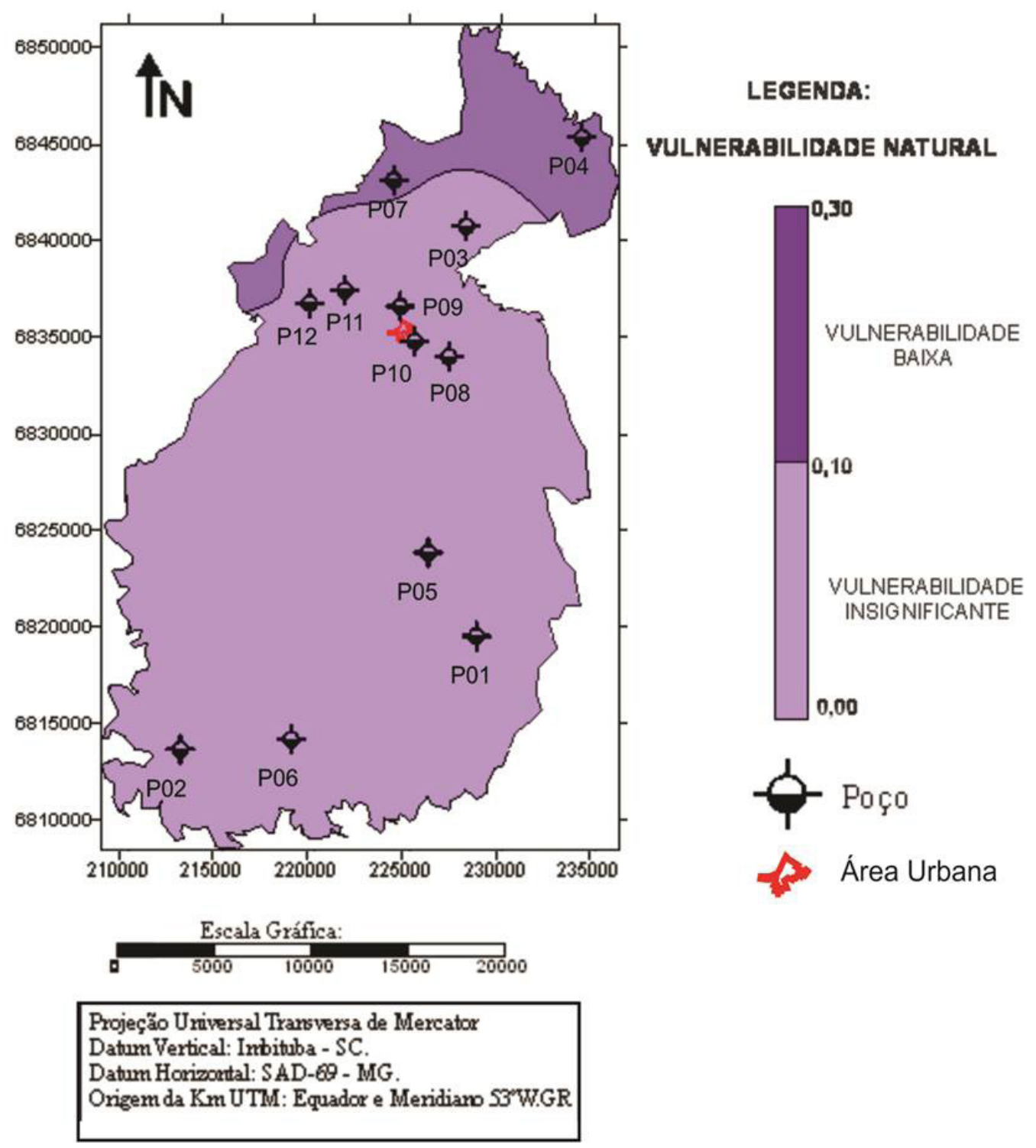

Figura 06 - Mapa da Vulnerabilidade do SASG à contaminação, no Município de Boa Vista do Cadeado/RS.

passa por Boa Vista do Cadeado, permeando várias localidades, chegando até o município de Ijuí, próximo ao entroncamento das rodovias ERS342, BR- 285 e ERS-522 (MONTARDO, 2011).

Fazendo-se uma avaliação da utilização do Sistema GOD (FOSTER et al., 2006). Notou-se uma ampla predominância de classe de vulnerabilidade insignificante em cerca de $83,3 \%$ da área estudada.

No mapa dos índices de vulnerabilidade natural do aquífero à contaminação (Figura 06), verifica-se que, na área de estudo, as porções situadas ao norte do cartograma são consideradas como de vulnerablidade baixa, incluindo as localidades de Faxinal (II), poço (P04) e na localidade de Rincão do Tigre poço (P07).

Lembrando-se que as faixas de vulnerabilidade insignificante e baixa (Quadro 03) não excluiem as ações de prevenção e de monitoramento no Decreto Estadual $n^{\circ} 42.047 / 2000$. Quanto a contaminantes conservadores, que tem ação acumulativa, de efeito à longo prazo. Devese efetivar a regulação e o controle das atividades onde são utilizados agrotóxicos, como por exemplo, a atividade agrícola, principalmente o cultivo do soja. Não se deve esquecer também as ações de saneamento, uma vez que os esgotos, não coletados e não tratados, poderão atingir o SASG, dependendo da intensidade da carga e da inacessibilidade do contaminante (FOSTER et al., 2003 e FOSTER et al., 2006). Conforme observado nos mapas a zona urbana não conta com captações por poços, mas estaria completamente inserida na classe insignificante (Figura 06), necessitando de cuidados no uso e ocupação dos solos.

Em visitas aos locais onde situavam-se as 
captaçoes dos 12 poços tubulares mapeados, verificou-se que a comunidade local é formada, em média por 15 unidades econômicas e a Prefeitura Municipal de Boa Vista do Cadeado, concentrou esforços para implantar o abastecimento na área ruaral do município por meio de poços tubulares, em diversas localidades. Porém observou-se, alguns detalhes construtivos, preconizados nas normas NBR`s 12.212/2006 e 12.244/2006, não foram atendidos na implantação da maioria dos poços tubulares cadastrados neste mapeamento (NASCIMENTO, 2013). Uma vez que a área estudada, apresenta geomorfologicamente um relevo acidentado, considerou-se a posição dos poços na paisagem, como: posição superior (entre $400-500) \mathrm{m}$, Intermediaria (entre $400-300 \mathrm{~m}$ ) e em posição inferior (entre 300 - $200 \mathrm{~m}$ ) (Quadro 01). Assim obtevesse na posição superior da área avaliada, $17 \%$ das captações, na inferior apenas $8 \%$ e a maior ocorrência, na posição intermediária, com cerca de $75 \%$ das captações.

Salienta-se ainda que várias captações por poços tubulares, não seguem a legislação estadual o Decreto n ${ }^{\circ} 42.047 / 2002$, não tendo sido ainda implantados os perímetros mínimos de proteção, o cercamento, o tubo lateral, o hidrômetro deixando o aquífero sob risco de alteração de sua qualidade natural, mesmo que com índices de vulnerabilidade baixa e insignificante.

\section{CONCLUSÕES}

No Município de Boa Vista do Cadeado foi possível espacializar, com uso do software SURFER 8.0®, duas classes de vulnerabilidade, com $83,3 \%$ das captações enquadradas na classe insignificante e, $16,7 \%$ na classe baixa, essa última predominando no setor norte da área de estudo. O sistema GOD foi considerado de fácil aplicação e forneceu resultados preditivos. Sempre sendo necessários estudos complementares relativos a alguma carga contaminante gerada na superfície do terreno, resultante de atividades antrópicas.

Por meio da espacialização dos dados hidrodinâmicos foi possível observar as zonas onde a água subterrânea, representada pelo seu nível estático, ocorre mais próxima da superfície do terreno. A superfície potenciométrica, traçada perpendicularmente as linhas equipotenciais, indica as direções preferenciais dos fluxos subterrâneos, de sudeste para sudoeste/nordeste, podendo atingir o curso de águas na localidade Beira Rio.

Há necessidade de adequação de quase todos os poços tubulares avaliados, principal- mente em relação as NBR-12.212/2006 e NBR12.244/2006 e ao Decreto Estadual n42.047/2002.

\section{AGRADECIMENTOS:}

Ao PPGEC/UFSM, A FAPERGS/CAPES.

\section{REFERÊNCIAS}

ABNT. ASSOCIAÇÃO BRASILEIRA DE NORMAS TÉCNICAS. NBR 6023. Informação e documentação: referências - elaboração. Rio de Janeiro: ABNT, 2002.

NBR 12244. Construção de poço para captação de água subterrânea. Rio de Janeiro: ABNT, 2006.

NBR 12212. Projeto de poço tubular para captação de água subterrânea. Rio de Janeiro: ABNT, 2006.

AGÊNCIA NACIONAL DE ÁGUAS (ANA). ATLAS BRASIL: abastecimento urbano de água: resultados por estado. Engecorps/Cobrape: Brasília, 2010.

ALLER, L., BENNET, T., LEHR, J. H., e PETTY, R. J. DRASTIC: A Standardized System

for Evaluating Groundwater Pollution Potential using Hydrogeologic Settings", EPA Report, v.

600, n.2, p $85-108.1987$

BRASIL. CONSELHO NACIONAL DE RECURSOS HÍDRICOS. Resolução n. 15 de 11 de janeiro de 2001. Delega competência a SINGRH e dá outras providências. Diário Oficial [da] República Federativa do Brasil, poder executivo, Brasília, DF, 2001. 03p.

CUSTODIO, E.; SILVA JUNIOR, G.C, Conceptos básicos sobre o papel ambiental das águas subterrâneas e os efeitos da sua explotação. Boletín Geológico y Minero. 119(1), 93- 106. 2008.

Ertel, T.; Lobler, C. A.; Silvério Da Silva, J. L. Índice de Vulnerabilidade das Águas Subterrâneas no Município de Rosário do Sul, Rio Grande do Sul. Revista Eletrônica em Gestão, Educação e Tecnologia Ambiental. , v.7, p. 1400 - 1408. 2012. 
BRASIL/SEMA/CAGE Secretaria do Meio Ambiente - DECRETO N ${ }^{\circ} 42.047$, DE 26 DE DEZEMBRO DE $2002<$ http://www.legislacao. sefaz.rs.gov.br/Site/Document.aspx?inpKey= 106552\&inpCodDispositive $=$ \&inpDsKeywords $=10350>$ Acesso em 11 de outubro de 2013

FOSTER, S; HIRATA, R; GOMES, D; D'ELIA, M; PARIS, M. Proteção da Qualidade da Água Subterrânea: um guia para empresas de abastecimento de água, órgãos municipais e agências ambientais. São Paulo, Servemar, 2006.

\section{HEATH, R.C. USGS Water Supply Paper} 2220, 1982. Disponível em http: . Visitado $1 / 10 / 2013$.

HEATH, R. C. Hidrologia Básica de Água Subterrânea. USGS Water Supply Paper 2220. Traduzição Mario Wrege e Paul Potter. Porto Alegre: UFRGS/ IPH, 1983.

IBGE - Instituto Brasileiro de Geografia e Estatística. Dados populacionais e da produção agrícola do município de Boa Vista do Cadeado, disponível em <http://www.ibge.gov.br> acesso em 01 fev. 2012.

Malha municipal digital do Brasil. Instituto Brasileiro de Geogra $\square$ a e Estatística. 2005.

KEMERICK, P. D. C.; SILVÉRIO DA SILVA, J.L.; DESCOVI FILHO, L. L. V.; VOLPATTO, SAUCEDO, E. M. Determinação da vulnerabilidade natural à contaminação da água subterrânea no Bairro Nossa Senhora do Perpétuo Socorro em Santa Maria-RS. Engenharia Ambiental (Online). v.1, p.085 - 098. 2011.

LANDIM, P. M. B.; MONTEIRO, R. C.; CORSI, A. C. Introdução à confecção de mapas pelo software SURFER. DGA, IGCE, UNESP/Rio Claro, Laboratório Geomatemática, Texto Didático 08, 21 p. 2002.

MACHADO, J.L.F. Compartimentação Espacial e Arcabouço Hidroestratigráfico do Sistema Aqüífero Guarani no Rio Grande do Sul. Tese de Doutorado. Programa de Pós-Graduação em Geologia. UNISINOS. São Leopoldo, 2005. 237 p.

MACHADO, J.L.F.; FREITAS, M.A. Projeto Mapa Hidrogeológico do Rio Grande do Sul: relatório final - Porto Alegre: CPRM, 2005.

MONTARDO, D.K. Laudo geológico na rodovia de acesso à sede de Boa Vista do Cadeado, RS. Assessoria Ambiental Gaia. Ijuí, 2011. Relatório Interno, impresso.

NANNI, A. S.; TEDESCO, M. A.; FREITAS, M. A., de; BINOTTO, R. B. Vulnerabilidade natural e risco de contaminação do aquífero subterrâneo Serra Geral pela suinocultura na Região das Missões - RS. In: XVI Simpósio Brasileiro de Recursos Hídricos, 2005, João Pessoa, 2005.

MARION, F. A.; MELLO FILHO, J. A. S.; SILVÉRIO SILVA, J. L. Análise da vulnerabilidade natural das águas subterrâneas por geoprocessamento no Campus da UFSM/ RS. Terr@ Plural (UEPG. Impresso), v.4, p.065 - 076. 2010.

MARTINEZ, M. M.; SILVÉRIO DA SILVA, J. L.; LOPES, G. N. Avaliação da Vulnerabilidade das Águas Subterrâneas no Município de Santa Cruz do Sul, RS/Brasil. Agro@mbiente On-line., v.2, p.1 - 8. 2008.

OEA; PEA; PSAG- Programa Estratégico da Ação. 2009. Disponível em <http://www.mma.gov.br/ ana>. Acesso em: 12 jan. 2012.

RIFFEL, E. S.; SILVÉRIO DA SILVA, J. L. Caracterização dos recursos hídricos subterrâneos no Município de Santa Rosa, RS. Revista do Departamento de Geografia, Universidade de São Paulo, v.22, p.3 - 28. 2011.

RIO GRANDE DO SUL (Estado). Constituição (1989). Constituição do Estado do Rio Grande do Sul. Porto Alegre: CORAG, 1989.

Decreto n. 42.047 de 26 de dezembro de 2002. Regulamenta disposições da Lei n. 10.350, de 30 de dezembro de 1994, com alterações, relativas ao gerenciamento e à conservação das águas subterrâneas e dos aquíferos no Estado do Rio Grande do Sul. Porto Alegre, dezembro 2002.

SILVÉRIO DA SILVA, J. L.; DESCOVI FILHO, L. L. V. (2010). Vulnerabilidade Das Águas Subterrâneas A Bacia Hidrográfica Do Rio Santa Maria-Rs. Revista Águas Subterrâneas., v.24, p.1 - 17.

SILVÉRIO DA SILVA, Jose Luiz ; Descovi ; LORENSI, R. P. ; CRUZ, Jussa Cabral ; ELTZ, F.L. . VULNERABILIDADE DO AQUÍFERO SERRA GERAL À CONTAMINAÇÃO NO MUNICIPIO DE ERECHIM - RIO GRANDE DO SUL - BRASIL. Ciência e Natura, v. 35, p. 10-23, 2013. 
TERRA, L. G.; LÖBLER, C. A.; SILVÉRIO DA

SILVA, J. L. Estimativa da Vulnerabilidade à Contaminação dos Recursos Hídricos Subterrâneos do Município de Santiago-RS. Revista Eletrônica em Gestão, Educação e Tecnologia Ambiental. , v.10, p.2208 - 2218. 2013. 